\title{
Protective effects of silymarin against bisphenol A-induced hepatotoxicity in mouse liver
}

\author{
MIHAELA ZAULET $^{1 *}$, STELIANA ELVIRA MARIA KEVORKIAN ${ }^{2 *}$, SORINA DINESCU $^{1 *}$, \\ CORALIA COTORACI ${ }^{3 *}$, MARIA SUCIU ${ }^{2}$, HILDEGARD HERMAN ${ }^{2}$, LAURA BUBURUZAN $^{4}$, \\ LILIANA BADULESCU ${ }^{5}$, AUREL ARDELEAN ${ }^{4}$ and ANCA HERMENEAN ${ }^{2,6}$ \\ ${ }^{1}$ Department of Biochemistry and Molecular Biology, University of Bucharest, 050095 Bucharest; \\ ${ }^{2}$ Department of Experimental and Applied Biology, Institute of Life Sciences; ${ }^{3}$ Department of Hematology, \\ Faculty of Medicine, Pharmacy and Dentistry; ${ }^{4}$ Department of Cell Biology, Faculty of Medicine, \\ 'Vasile Goldiș' Western University of Arad, 310414 Arad; ${ }^{5}$ Department of Bioengineering of Horti-Viticultural System, \\ University of Agronomical Science and Veterinary Medicine, 011464 Bucharest; \\ ${ }^{6}$ Department of Histology, Faculty of Medicine, 'Vasile Goldiș’ Western University of Arad, 310414 Arad, Romania
}

Received November 8, 2015; Accepted June 23, 2016

DOI: 10.3892/etm.2017.4066

\begin{abstract}
Bisphenol A (BPA) is an endocrine-disrupting chemical released into the environment, with severe consequences for human health, including metabolic syndrome and associated pathological conditions. Due to limited information on BPA-induced hepatotoxicity, the present study focused on investigating the association between BPA-induced toxicity and inflammatory markers in the liver, and how these injuries may be alleviated using the natural agent silymarin, a flavonoid with antioxidant properties obtained from Silybum marianum. Administration of BPA to male CD-1 mice for 10 days caused a significant increase in the number of cells immunopositive for interleukin 6 and tumor necrosis factor- $\alpha$, pro-inflammatory cytokines that mediate the hepatic inflammatory response. Treatment with $200 \mathrm{mg} / \mathrm{kg}$ of silymarin concurrently with BPA for 10 days resulted in a diminished level of pro-inflammatory cytokines and in significantly reduced ultrastructural injuries. Additionally, silymarin was able to restore the significantly decreased glycogen deposits observed following BPA exposure to normal levels, thus favoring hepatic glycogenesis. This study represents the first report of silymarin ability to reduce hepatic lesions and to counteract inflammation caused by BPA in mice. A dose of $200 \mathrm{mg} / \mathrm{kg}$ silymarin was sufficient to induce a protective effect against structural and ultra-
\end{abstract}

Correspondence to: Dr Anca Hermenean, Department of Histology, Faculty of Medicine, 'Vasile Goldiș' Western University of Arad, 86 Rebreanu Street, 310414 Arad, Romania

E-mail: anca.hermenean@gmail.com

*Contributed equally

Key words: pro-inflammatory cytokines, silymarin, bisphenol A, hepatotoxicity, hepatoprotection structural injuries induced by BPA and to lower the levels of pro-inflammatory cytokines observed in murine liver tissue following exposure to BPA.

\section{Introduction}

The liver is involved in the major biochemical and signaling pathways associated with homeostasis (1) and plays a crucial role in interacting with and fighting against xenobiotics. Among these, bisphenol A (BPA) is a fairly ubiquitous compound with certain risks to human health, which have aroused public concern.

In the liver, BPA is metabolized and eliminated essentially as a monoglucuronide (the major metabolite) and/or as a sulfate conjugate. However in Fischer-344 rat hepatocytes, BPA is converted primarily to a diconjugate (glucuronide/sulfate) (2). The hepatic capacity for BPA glucuronidation is predicted to be greater in humans than in rats and mice (2).

Structurally, BPA imitates estrogen and causes dysfunction of the reproductive organs $(3,4)$, having a potential role in severe pathologies such as breast cancer (5). Additionally, exposure to BPA has been associated with various diseases, including cardiovascular disease (6), type II diabetes, altered insulin homeostasis, abnormal liver function (6) and cancer (7). In particular, the detrimental interaction of BPA with genes associated with adipose tissue and obesity has been linked with metabolic syndrome and associated pathological conditions $(8,9)$. In this context, low-grade chronic inflammation has been identified as a key pathogenic connection between metabolic syndrome, obesity and insulin resistance $(10,11)$. Interleukin (IL)- 6 and tumor necrosis factor (TNF)- $\alpha$ are considered pro-inflammatory markers, useful for the identification of low-grade inflammation associated with visceral adiposity (11). Additionally, concerns regarding the presence of BPA in food and the environment have been constantly rising since the dose-dependent incidence of hepatic tumors following perinatal exposure to BPA was reported in isogenic 
mouse models (12). Notably, it has previously been shown that BPA has the ability to dysregulate cytokines (13), induce cellular apoptosis in hepatocytes (14) and produce oxidative stress in liver tissue $(15,16)$.

Natural compounds extracted from plants have often been found to have efficient protective and preventive effects against pathological conditions. A flavonoid with important antioxidant properties isolated from the milk thistle Silybum marianum seeds is silymarin. Apart from its anti-inflammatory effect (17), silymarin has been shown to protect against hepatotoxicity induced by numerous different agents: Excess iron (18), manganese (19), ethanol (20), carbon tetrachloride $(21,22)$, acetaminophen (paracetamol) (23) and anticancer agents as cisplatin (24), epirubicin (25) and doxorubicin (26). The hepatoprotective and antioxidant activity of silymarin has been attributed to its capacity to eliminate free radicals produced during the hepatic metabolism of toxic substances through the inhibition of the cyclooxygenase cycle and leukotrienes (27). Moreover, this flavonoid has a phenolic structure, which allows electron donation to free radicals and reactive oxygen species (ROS) in order to stabilize them and prevents lipid peroxidation by interaction with intracellular glutathione (27,28). Additionally, silymarin has previously been reported to have anti-proliferative, anti-fibrotic, anti-apoptotic, antiviral and immunomodulatory properties $(25,29)$ and has been shown to inhibit TNF- $\alpha$ expression (30).

The present study aimed to quantify the pro-inflammatory effects of BPA on mouse liver tissue and to propose a potential counteracting agent against the hepatotoxic and inflammatory stress exerted by BPA, namely silymarin. To the best of our knowledge, this is the first study investigating i) the connection between BPA-induced toxicity and low-grade chronic inflammatory markers in the liver and ii) the potential beneficial effect of silymarin in protecting against BPA-induced liver damage.

\section{Materials and methods}

Chemicals. Bisphenol A 99\%, silymarin 98\% and carboxymethyl cellulose were purchased from Sigma-Aldrich Chemie GmbH (Munich, Germany). TNF- $\alpha$ (sc-52746) and IL-6 (sc-1265-R) antibodies were supplied by Santa Cruz Biotechnology, Inc. (Dallas, TX, USA). A Novocastra kit for immunohistochemistry (Novolink Max Polymer Detection System; RE7280-K) was purchased from Leica Microsystems GmbH (Wetzlar, Germany).

Animals. Male CD-1 mice ( $\mathrm{n}=40$; age, 8-10 weeks; body weight, $25 \pm 3 \mathrm{~g}$ ) from a breeding colony at the Animal Facility at 'Vasile Goldiș' Western University of Arad (Arad, Romania) were fed a standard rodent diet and maintained under a $12 \mathrm{~h} \mathrm{light/dark} \mathrm{cycle,} \mathrm{with} \mathrm{a} \mathrm{constant} \mathrm{temperature}$ $\left(20 \pm 1^{\circ} \mathrm{C}\right)$ and humidity $(50 \pm 5 \%)$. All experimental procedures were performed in compliance with the appropriate laws and institutional guidelines, and were approved by the Institutional Ethics Committee of Vasile Goldiş Western University of Arad (Arad, Romania).

Experimental design. For analyzing the effect of silymarin on BPA-induced hepatotoxicity, mice were randomly divided into four groups $(\mathrm{n}=10)$ : Control, BPA, bisphenol A+silymarin (BPA+SY) and silymarin (SY) groups. Silymarin powder was dissolved in $0.7 \%$ carboxymethyl cellulose and BPA in 5\% ethanol, diluted with corn oil. Vehicles were administered by gavage daily for 10 days to mice in the control group. A dose of $200 \mathrm{mg} / \mathrm{kg}$ BPA (31) was administered daily by gavage to mice in the BPA and BPA+SY groups, between days 1 and 10. Silymarin was administered daily for 10 days, at a dose of $200 \mathrm{mg} / \mathrm{kg}$, to mice in the BPA+SY and SY groups.

All mice were sacrificed on day 11 of the experiment. The mice were anesthetized with ketamine $(100 \mathrm{mg} / \mathrm{kg})$ and xylazine $(10 \mathrm{mg} / \mathrm{kg})$ administered intraperitoneally and sacrificed by cervical dislocation. Liver samples were collected and preserved in a buffered formalin solution for histology and immunohistochemistry or in glutaraldehyde solution for electron microscopy examination.

Histopathology. Liver specimens were fixed in $4 \%$ phosphate-buffered formalin, embedded in paraffin and cut into 4- $\mu \mathrm{m}$ sections. Sections for histopathological examination were stained with hematoxylin and eosin, and analyzed by light microscopy using an Olympus BX43 System Microscope (Olympus, Hamburg, Germany) and photographic images were captured using a digital camera (Olympus XC30).

Immunohistochemistry. Paraffin-embedded liver tissue sections of 5- $\mu \mathrm{m}$ thickness were deparaffinized and rehydrated in decreasing concentrations of ethyl alcohol. Rabbit polyclonal anti-TNF- $\alpha$ and anti-IL- 6 antibodies (1:100 dilution) were used as primary antibodies. Immunoreactions were visualized employing a Novocastra immunohistochemistry kit with peroxidase and diaminobenzidine chromogen according to the manufacturer's instructions. Negative control slides were processed by the substitution of primary antibodies with irrelevant immunoglobulins of matched isotype, under the same conditions as those used for the primary antibodies. Stained sections were analyzed by light microscopy (Olympus BX43).

Gene expression analysis by reverse transcription-quantitative polymerase chain reaction ( $R T-q P C R)$. Liver samples were collected from the mice and total RNA was isolated using an RNeasy Mini kit (Qiagen GmbH, Hilden, Germany) according to the manufacturer's protocol. Extracted RNA was tested for integrity using a 2100 BioAnalyzer instrument (Agilent Technologies GmbH, Waldbronn, Germany) and purity using a NanoDrop spectrophotometer (Thermo Scientific, Inc., Waltham, CA, USA), then reverse transcribed to corresponding cDNA using an iScript cDNA Synthesis kit (Bio-Rad Laboratories, Inc., Hercules, CA, USA). qPCR was performed on a Rotor-Gene thermocycler using a Rotor-Gene SYBR Green RT-PCR Kit (Qiagen GMBH, Hilden, Germany) and the following thermal cycling conditions: $3 \mathrm{~min}$ at $95^{\circ} \mathrm{C}$, followed by 40 cycles of $30 \mathrm{sec}$ at $95^{\circ} \mathrm{C}, 30 \mathrm{sec}$ at $62^{\circ} \mathrm{C} 45 \mathrm{sec}$ at $72^{\circ} \mathrm{C}, 60 \mathrm{sec}$ at $95^{\circ} \mathrm{C}, 10 \mathrm{sec}$ at $55^{\circ} \mathrm{C}$ and cooling to $20^{\circ} \mathrm{C}$. The sequences of the primers used for TNF- $\alpha$ and IL-6 mRNA detection are presented in Table I. mRNA levels of target genes were normalized to the levels of glyceraldehyde 3-phosphate dehydrogenase (GAPDH), which was used as reference gene and was assessed under the same experimental conditions. Additionally, transcript levels of the target 
Table I. Primer sequences used to identify TNF- $\alpha$ and IL-6 inflammatory markers by RT-qPCR.

\begin{tabular}{ll} 
Target & \multicolumn{1}{c}{ Primer sequence (5' to $3^{\prime}$ ) } \\
\hline TNF- $\alpha$ & F: CAGGTTCTCTTCAAGGGACAAG \\
& R: GCAGAGAGGAGGTTGACTTTC \\
IL-6 & F: GCAGAGAGGAGGTTGACTTTC \\
& R: GACAGGTCTGTTGGGAGTGGTATC \\
GAPDH & F: AGGTCGGTGTGAACGGATTTG \\
& R: TGTAGACCATGTAGTTGAGGTCA
\end{tabular}

TNF, tumor necrosis factor; IL, interleukin; RT-qPCR, reverse transcription-quantitative polymerase chain reaction; GAPDH, glyceraldehyde 3-phosphate dehydrogenase; F, forward; R, reverse.

inflammation markers were compared with the mRNA levels of the same markers from the control group.

Electron microscopy. Samples were prefixed with $2.7 \%$ glutaraldehyde solution in $0.1 \mathrm{M}$ phosphate buffer at $4^{\circ} \mathrm{C}$ for $1.5 \mathrm{~h}$, washed in $0.15 \mathrm{M}$ phosphate buffer and postfixed in $2 \%$ osmic acid solution in $0.15 \mathrm{M}$ phosphate buffer. Dehydration was performed in acetone and the sections were embedded in the epoxy embedding resin Epon 812. Sections of thickness $60 \mathrm{~nm}$ were cut with a Leica EM UC7 ultramicrotome (Leica Microsystems $\mathrm{GmbH}$ ) and analyzed with a Tecnai 12 Biotwin transmission electron microscope.

Statistical analysis. Gene expression data were statistically evaluated using GraphPad Prism 3.03 software (GraphPad Software, Inc., La Jolla, CA, USA), and one-way analysis of variance, followed by a Bonferroni test. $\mathrm{P}<0.05$ was considered to indicate a statistically significant difference. The experiments were performed with $\mathrm{n}=10$ biological replicates and each data set is presented as the average of three replicates (mean \pm standard deviation).

\section{Results}

Protective effects of silymarin against hepatotoxicity induced by BPA. Histopathological examination and comparison with the control (Fig. 1A), revealed that BPA administration induced necrotic changes of hepatocytes, which were particularly pronounced in the centrilobular area (Fig. 1B). Inflammatory cell infiltration and vascular congestion were also present. In the BPA+SY group, 10 days of $200 \mathrm{mg} / \mathrm{kg}$ silymarin administration markedly reduced the hepatocellular changes, as compared with those in the BPA group, and the morphology was not dissimilar to that of the SY group (Fig. 1C). The liver morphology of the SY group (Fig. 1D) was comparable with that of the control group (Fig. 1A).

Protective effects of silymarin against TNF- $\alpha$ and IL-6 hepatic overexpression induced by BPA. Immunohistochemical and gene expression analyses were performed to evaluate the impact of silymarin treatment on the regulation of IL- 6 and TNF- $\alpha$ under BPA pro-inflammatory activity. As shown in
Figs. 2 and 3, compared with the control (Figs. 2A and 3A), the administration of BPA caused a significant increase in the number of parenchymal cells immunopositive for IL- 6 and TNF- $\alpha$ (Figs. 2B and 3B). No apparent IL- 6 or TNF- $\alpha$ expression was detected in non-parenchymal cells. In the BPA+SY group, silymarin treatment decreased the number of cells labeled with both antibodies, compared with the BPA group (Figs. 2C and 3C). No immunopositivity for the group treated with SY alone was detected (Figs. 2D and 3D).

These findings were confirmed by the results of IL- 6 and TNF- $\alpha$ RT-qPCR analysis (Figs. 2E and 3E). Evaluation by qPCR demonstrated that exposure to BPA induced high transcript levels of IL-6 in mouse liver tissue (a 1.6-fold increase compared with the control), thus confirming that BPA exerts a hepatotoxic and pro-inflammatory effect (Fig. 2E). Treatment with the natural compound silymarin resulted in very low levels of IL-6 mRNA, comparable with the control. Notably, a statistically significant lower level of IL-6 transcript $(\mathrm{P}<0.01)$ was found in livers isolated from mice exposed to a 1:1 ratio of BPA and SY for 10 days, when compared with IL-6 expression in the BPA group. However, a significant difference in IL-6 expression $(\mathrm{P}<0.01)$ was observed between mice exposed simultaneously to SY and BPA and those exposed only to SY.

Furthermore, the pro-inflammatory effect of BPA triggered similar changes in IL- 6 and TNF- $\alpha$ transcript levels in mouse hepatic tissue after 10 days of treatment. SY administration for the same interval resulted in a low level of TNF- $\alpha$ expression, significantly lower than the levels obtained for dual BPA and SY exposure $(\mathrm{P}<0.05)$. Overall, the TNF- $\alpha$ mRNA levels detected by qPCR in mice treated with both BPA and SY were statistically significantly lower than those in mice treated only with BPA (P<0.05; Fig. 3E).

Protective effects of silymarin against ultrastructural hepatic injuries induced by BPA. Fig. 4 shows that the ultrastructure of hepatocytes was normal in the control group (Fig. 4A) and SY group (Fig. 4G), showing regular organelles and cytoplasmic glycogen deposition. In the BPA-treated group, the majority of the hepatocytes exhibited irregular nuclear shapes, together with damaged rough endoplasmic reticulum (rER), irregular mitochondria and reduced glycogen deposits (Fig. 4B). Some hepatocytes displayed dilated bile canaliculi, voided of microvilli (Fig. 4C). Liver-infiltrating lymphocytes were present in many micrographs (Fig. 4D).

Treatment with $200 \mathrm{mg} / \mathrm{kg}$ SY for 10 days significantly reduced the ultrastructural injuries induced by BPA co-administration (Fig. 4E and F). Organelle and cytoplasm structures were widely protected against the effects of BPA. Abnormal irregular nuclear shapes and dilated bile canaliculi were not visible in the SY+BPA group. Glycogen deposits were increased, while the cytoplasmic distribution of mitochondria and rER was restored. However, proliferation of smooth reticulum vesicles was present (Fig. 4E).

\section{Discussion}

BPA is an endocrine-disrupting chemical prevalent in the environment, and previous studies have focused on its effects on reproduction $(32,33)$. Due to limited information concerning the toxic effect on the liver, the present study focused on 

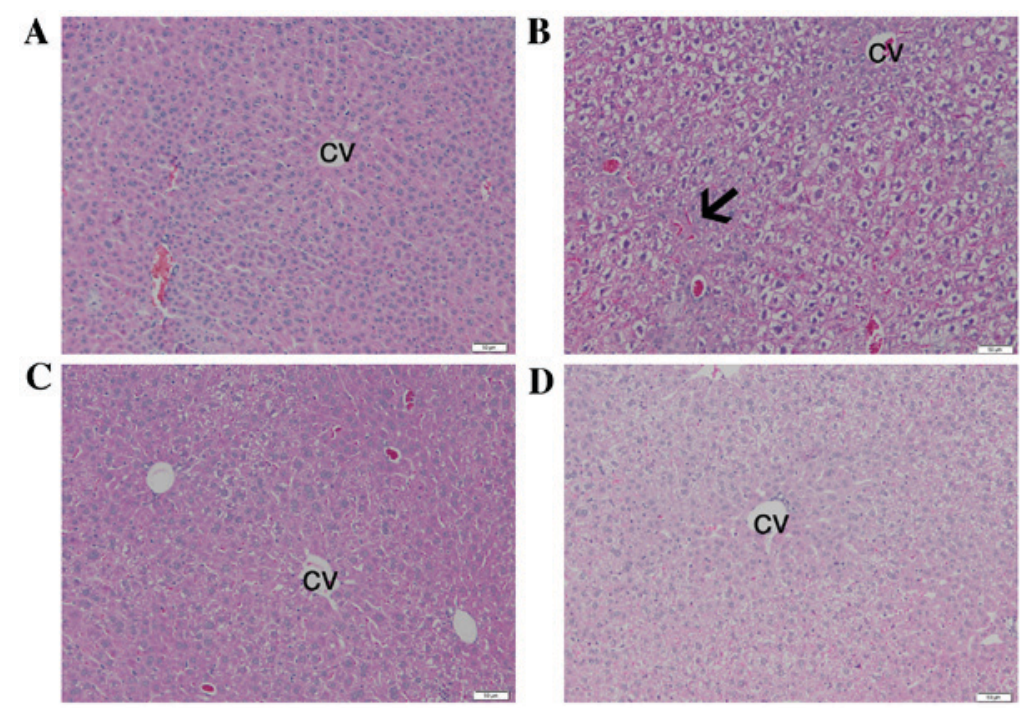

Figure 1. Effect of SY on histological changes in the livers of BPA-treated mice. (A) Control group, (B) BPA group, (C) BPA+SY group and (D) SY group. The arrow indicates vascular congestion. Hematoxylin and eosin staining. Scale bar, $50 \mu \mathrm{m}$. SY, silymarin; BPA, bisphenol A; CV, centrilobular vein.
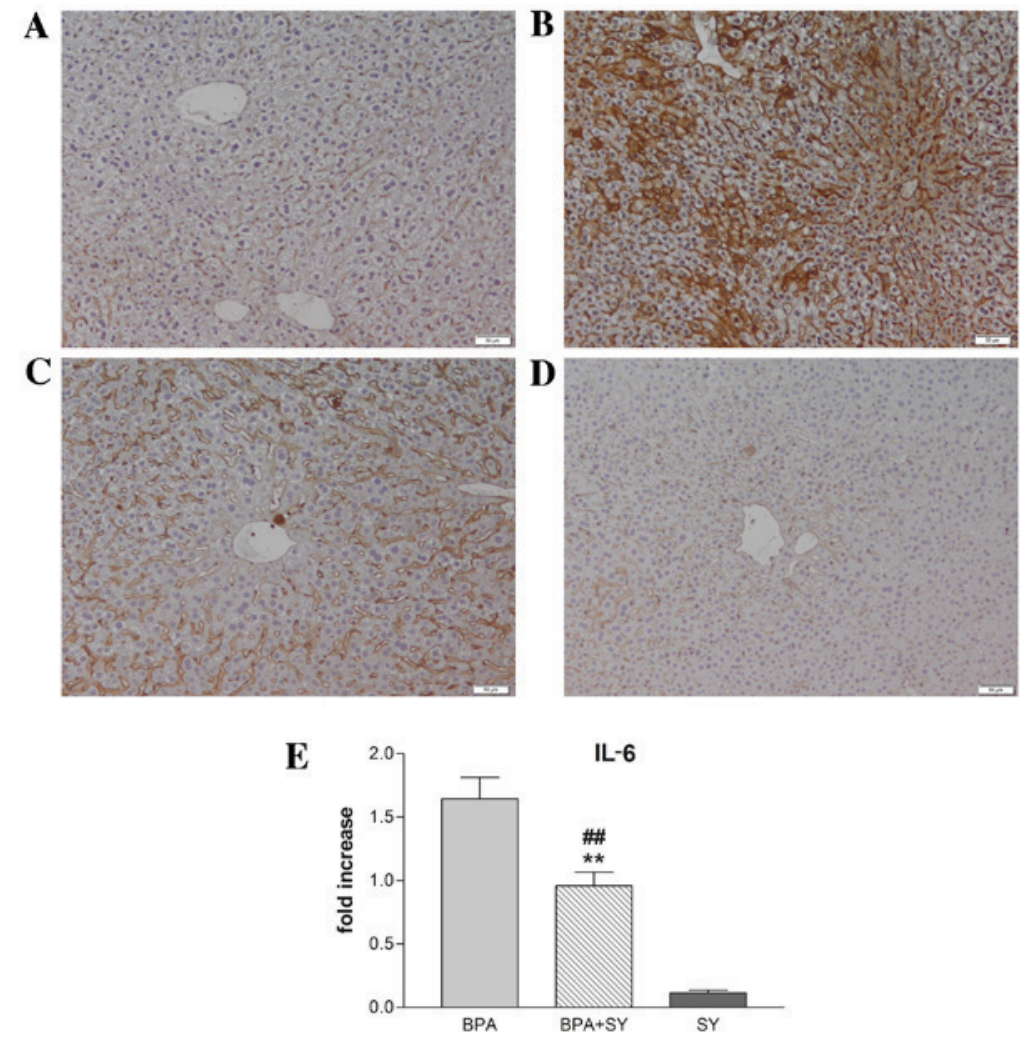

Figure 2. Suppression of IL-6 by SY in the livers of BPA-treated mice. (A-D) Expression and specific tissue distribution of IL-6 in the experimental groups as revealed by immunohistochemical (diaminobenzidine) staining. (A) In control livers, IL-6 expression was negligible. (B) Strong IL-6 immunopositivity was visible in the parenchymal cells of BPA-treated mice. (C) Reduced IL-6 immunopositivity was observed in mice treated with BPA+SY, compared with the BPA group. (D) Livers of mice receiving SY alone were comparable to the controls. (E) IL-6 gene expression in the experimental groups. Values are presented as mean \pm standard deviation $(\mathrm{n}=10){ }^{* *} \mathrm{P}<0.01$ vs. the BPA group; ${ }^{\# \#} \mathrm{P}<0.01$ vs. the SY group. IL, interleukin; SY, silymarin; BPA, bisphenol A.

evaluating the toxic effect of BPA and investigating the potential alleviation of BPA-induced injuries using a natural agent. The present study represents the first report of the ability of silymarin to reduce hepatic lesions and to counteract inflammation caused by BPA administration in animal models. The target of the study was to explore whether a dose of $200 \mathrm{mg} / \mathrm{kg}$ silymarin is sufficient to induce a protective effect against structural and ultrastructural injuries induced by BPA and to lower the levels of pro-inflammatory cytokines observed in murine liver tissue following exposure to BPA for 10 days.

Acute hepatotoxicity induces inflammatory effects and hepatocyte apoptosis or necrosis. The necrotic pericentrilob- 

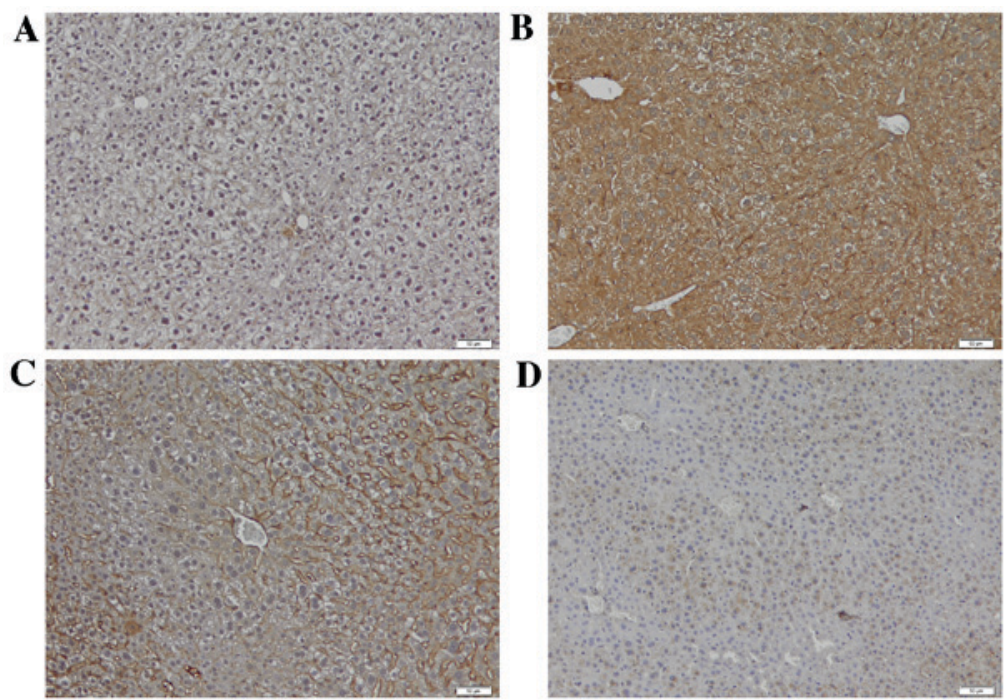

$\mathbf{E}$

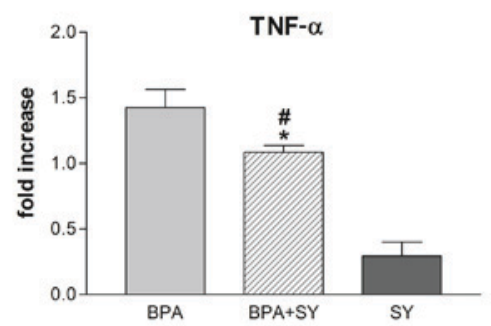

Figure 3. Suppression of TNF- $\alpha$ by SY in the livers of BPA-treated mice. (A-D) Expression and specific tissue distribution of TNF- $\alpha$ in the experimental groups as revealed by immunohistochemical (diaminobenzidine) staining. (A) In the control livers, TNF- $\alpha$ expression was negligible. (B) Strong TNF- $\alpha$ immunopositivity was visible in the parenchymal cells of BPA-treated mice. (C) Reduced TNF- $\alpha$ immunopositivity was observed in mice treated with BPA+SY, compared with the BPA group. (D) The livers of mice receiving SY alone were comparable to the controls. (E) TNF- $\alpha$ gene expression in the experimental groups. Values are presented as mean \pm standard deviation $(n=10)$. ${ }^{*} \mathrm{P}<0.05$ vs. the BPA group; ${ }^{\#} \mathrm{P}<0.05$ vs. the $\mathrm{SY}$ group. TNF, tumor necrosis factor; $\mathrm{SY}$, silymarin; BPA, bisphenol A.

ular changes, vascular congestion and inflammation observed in histological liver sections are naturally occurring reactions of the system to cell damage (34-36), as also shown by the histopathological and immunohistochemical results of the present study.

The hepatic inflammatory response is mediated by proinflammatory cytokines, especially $\mathrm{TNF}-\alpha$, the release of which is one of the first events in many types of liver injury, and further modulates the effects of other cytokines, such as IL-6 (37). IL-6 is the predominant regu-lator of the hepatic acute-phase response and modulates liver fibrosis through degrading extracellular matrix proteins by protease inhibition or cytokine binding $(38,39)$. The present study showed that IL- 6 and TNF- $\alpha$ are stimulatory, as suggested by higher levels in hepatic tissue and upregulation of their mRNA in mice with BPA-induced liver acute inflammation. Previous data have shown a significant correlation between BPA and inflammatory markers such as IL-6 and TNF- $\alpha$ (11). This previous study, involving a homogenous adult male population in southern Italy, revealed that higher BPA plasma levels are associated with higher levels of circulating IL-6 and TNF- $\alpha$ pro-inflammatory cytokines.

Following the administration of $200 \mathrm{mg} / \mathrm{kg}$ daily doses of silymarin for 10 days, the present study demonstrated an overall diminished level of IL- 6 and TNF- $\alpha$ pro-inflammatory cytokines in mouse liver tissue and attenuation of the inflammatory process. By studying the transcript levels and protein expression of IL-6 and TNF- $\alpha$ pro-inflammatory markers, the present study confirmed at quantitative and qualitative levels a significant reduction in the levels of IL-6 $(\mathrm{P}<0.01)$ and TNF- $\alpha$ $(\mathrm{P}<0.05)$ in the group exposed to BPA and SY in equal proportions, as compared with the group that received only BPA. This data is in accordance with previous results found in the literature, confirming the anti-inflammatory and hepatoprotective effect of silymarin against toxic substances $(40,41)$. Similarly, a study assessing the toxic effects of sodium nitrate food additive in rat liver (40) has identified significant increases in hepatic TNF- $\alpha$ and IL- $1 \beta$ levels in rats exposed to sodium nitrate as compared with their levels in a control group. The co-administration of $80 \mathrm{mg} / \mathrm{kg}$ sodium nitrite and $25 \mathrm{mg} / \mathrm{kg}$ silymarin for 12 weeks resulted in significant reductions of TNF- $\alpha$ and IL-1 $\beta$ hepatic concentrations, similar to observations in the present study, suggesting that silymarin has a dose-dependent beneficial effect against the impairment of liver function.

The anti-inflammatory effect of silymarin on the liver is supported by additional research. A study using murine knock-out cells (41) revealed that nuclear factor- $\kappa \mathrm{B}$, a key transcription factor considered to play a crucial role in the cellular response to signal transduction by TNF- $\alpha$ and IL-6 (42), was inhibited through reparative stress signaling. It was concluded that silymarin activates stress and repair responses, which correlates with the ability to suppress inflammation.

The cytotoxic effects of BPA are strongly linked with the production of ROS in liver, kidney and brain tissue, as previ- 

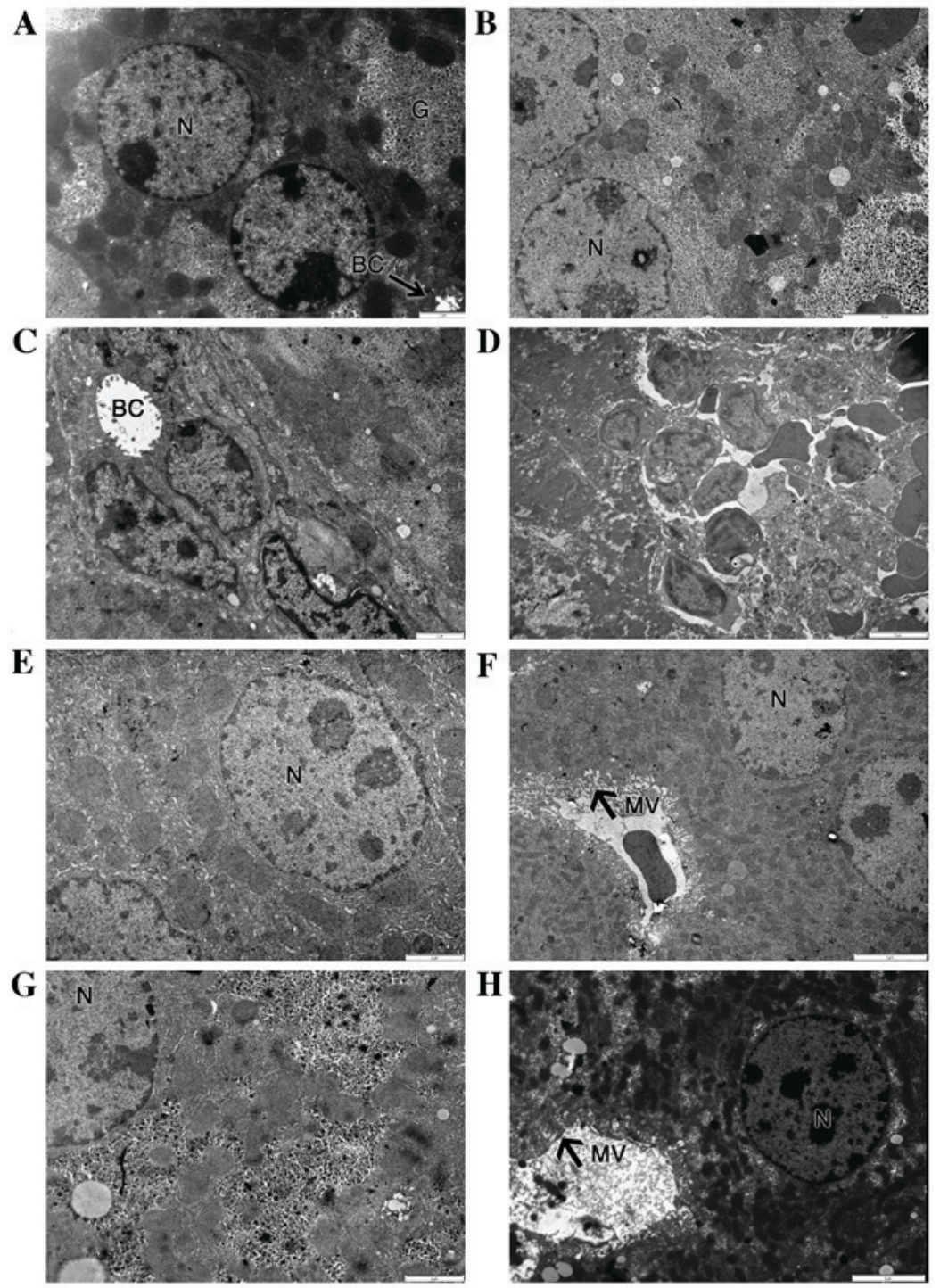

Figure 4. Effect of SY on BPA-induced ultrastructural changes in the livers of mice. (A) Control group: Hepatocytes appear normal. (B-D) BPA group: (B) Hepatocytes appear altered with irregular nuclear shapes, reduced glycogen deposition, (C) dilated bile canaliculi without microvilli and (D) infiltrating lymphocytes into parenchyma. (E and F) BPA+SY group: (E) Normal appearance of organelles and glycogen deposits, and (F) evident microvilli. (G and H) SY group: Aspects are comparable with those of control hepatocytes. SY, silymarin; BPA, bisphenol A; N, nucleus; BC, biliary canaliculi; MV, microvilli.

ously documented $(15,43)$. The effects of BPA on the liver have been particularly tested, since the liver is the major site exposed to toxicants and oxidative stress, although it possesses an endogenous antioxidant defense system. A study in rats has confirmed that liver damage following exposure to BPA is mainly due to BPA affecting the oxidant/antioxidant balance in the liver (44). Oxidative stress effects are followed by ultrastructural injuries. In the present study, BPA administration caused hepatocyte damage, which resulted in nuclear changes and other organelle impairments. The changes in hepatocyte ultrastructure were probably due to injuries of the membrane structure caused by lipid peroxidation. A parallel study (45) concluded that BPA-induced oxidative stress is similar to the stress produced by hydrogen peroxide. The mechanism proposed for the oxidative-stress increase is based on the lipophilic nature of BPA (46); BPA is likely to interact with the hydrophobic cell plasma membrane, initiating hydroxyl radical formation and the induction of lipid peroxidation (45). Xia et al (47) demon- strated that BPA induces mitochondria-mediated apoptosis in hepatic cells.

The aforementioned hepatocyte injuries were alleviated by silymarin administration, suggesting that silymarin acts as a free-radical scavenger, while other studies have demonstrated its liver protection effects against paracetamol $(23,48)$, carbon tetrachloride $(21,22)$, anticancer agents $(25,26)$ and lipid peroxidation (27), by enhancement of anti-oxidant status.

Furthermore, the ultrastructural analysis conducted in the present study recorded a significant reduction of glycogen deposits in the BPA group, while a previous study suggested that BPA treatment impairs hepatic glucose oxidation and glycogen content through defective insulin signal transduction (49). Consistent with observations in the present study, significant depletion of glycogen stores has also been reported in the liver tissue of adult male albino rats following 2 weeks of exposure to cisplatin (50). Notably, this previous study and the present one found that silymarin was able to counteract 
toxicant activity and restore glycogen to normal levels, thus favoring hepatic glycogenesis. It is generally considered that a harmful toxicant produces enough cellular stress in hepatocytes that glycogenolysis is activated in order to generate increased glucose serum levels (51), which protects cells from oxidative injury (52). This was reported by several groups following cisplatin administration and monitoring of its effects on hepatocytes $(50,53,54)$. The underlying mechanism supporting glycogen formation in the presence of silymarin is not completely known; however, it has been proposed that silymarin ameliorates the principal functions of the liver, which are associated with the regulation of carbohydrate metabolism, by restoring serum glucose levels to normal values $(50,55)$.

In conclusion, numerous studies have promoted the exploration of the potential of natural extracts against the negative effects produced by toxicants or pharmacologically harmful compounds in tissues. In this perspective, silymarin has exhibited efficient results in various types of tissues, but particularly in the liver where it can control oxidative, glucidic and lipid metabolism. The current study confirms the hepatoprotective effect of silymarin against exposure to BPA and highlights for the first time its ability to counteract low-grade inflammation caused by BPA administration in animal models. Thus, silymarin holds great promise as an adjuvant therapy for hepatotoxicity, and could be a useful tool to further investigate the mechanism by which metabolic signaling pathways regulate cellular inflammation.

\section{Acknowledgements}

This study was supported by a strategic grant (no. POSDRU/159/1.5/S/133391)Project 'DoctoralandPost-doctoral programs of excellence for highly qualified human resources training for research in the field of Life sciences, Environment and Earth Science' cofinanced by the European Social Fund within the Sectorial Operational Program Human Resources Development 2007-2013. This study was also financed by the Institute for Research of the University of Bucharest (ICUB), through 'Scholarships for Excellence in Research for Young Researchers, 2015 Competition' Project and START Project: BEST-NetWORK 16_PA07-C1.

\section{References}

1. Abdel-Wahab WM: Thymoquinone attenuates toxicity and oxidative stress induced by bisphenol A in liver of male rats. Pak J Biol Sci 17: 1152-1160, 2014.

2. Pritchett JJ, Kuester RK and Spies IG: Metabolism of bisphenol A in primary cultured hepatocytes from mice, rats, and humans. Drug Metab Dispos 30: 1180-1185, 2002.

3. Takeuchi T, Tsutsumi O, Ikezuki Y, Takai Y and Taketani Y: Positive relationship between androgen and the endocrine disruptor, bisphenol $\mathrm{A}$, in normal women and women with ovarian dysfunction. Endocr J 51: 165-169, 2004.

4. Mendiola J, Jørgensen N, Andersson AM, Calafat AM, Ye X, Redmon JB, Drobnis EZ, Wang C, Sparks A, Thurston SW, et al: Are environmental levels of bisphenol a associated with reproductive function in fertile men? Environ Health Perspect 118: 1286-1291, 2010.

5. Pupo M, Pisano A, Lappano R, Santolla MF, De Francesco EM, Abonante S, Rosano C and Maggiolini M: Bisphenol A induces gene expression changes and proliferative effects through GPER in breast cancer cells and cancer-associated fibroblasts. Environ Health Perspect 120: 1177-1182, 2012.
6. Lang IA, Galloway TS, Scarlett A, Henley WE, Depledge M, Wallace RB and Melzer D: Association of urinary bisphenol A concentration with medical disorders and laboratory abnormalities in adults. JAMA 300: 1303-1310, 2008.

7. Duan B, Hu X, Zhao H, Qin J and Luo J: The relationship between urinary bisphenol A levels and meningioma in Chinese adults. Int J Clin Oncol 18: 492-497, 2013.

8. Rubin BS: Bisphenol A: An endocrine disruptor with widespread exposure and multiple effects. J Steroid Biochem Mol Biol 127: 27-34, 2011.

9. Vom Saal FS, Nagel SC, Coe BL, Angle BM and Taylor JA: The estrogenic endocrine disrupting chemical bisphenol A (BPA) and obesity. Mol Cell Endocrinol 354: 74-84, 2012

10. Rodríguez-Hernández H, Simental-Mendía LE, Rodríguez-Ramírez G and Reyes-Romero MA: Obesity and inflammation: Epidemiology, risk factors, and markers of inflammation. Int J Endocrinol 2013: 678159, 2013.

11. Savastano S, Tarantino G, D'Esposito V, Passaretti F, Cabaro S, Liotti A, Liguoro D, Perruolo G, Ariemma F, Finelli C, et al: Bisphenol-A plasma levels are related to inflammatory markers, visceral obesity and insulin-resistance: A cross-sectional study on adult male population. J Transl Med 13: 169, 2015.

12. Weinhouse C, Anderson OS, Bergin IL, Vandenbergh DJ, Gyekis JP, Dingman MA, Yang $J$ and Dolinoy DC: Dose-dependent incidence of hepatic tumors in adult mice following perinatal exposure to bisphenol A. Environ Health Perspect 122: 485-491, 2014.

13. Wetherill YB, Akingbemi BT, Kanno J, McLachlan JA, Nadal A, Sonnenschein C, Watson CS, Zoeller RT and Belcher SM: In vitro molecular mechanisms of bisphenol A action. Reprod Toxicol 24: 178-198, 2007.

14. Asahi J, Kamo H, Baba R, Doi Y, Yamashita A, Murakami D, Hanada A and Hirano T: Bisphenol A induces endoplasmic reticulum stress-associated apoptosis in mouse non-parenchymal hepatocytes. Life Sci 87: 431-438, 2010.

15. Bindhumol V, Chitra KC and Mathur PP: Bisphenol A induces reactive oxygen species generation in the liver of male rats. Toxicology 188: 117-124, 2003.

16. Moon MK, Kim MJ, Jung IK, Koo YD, Ann HY, Lee KJ, Kim SH, Yoon YC, Cho BJ and Park KS: Bisphenol a impairs mitochondrial function in the liver at doses below the no observed adverse effect level. J Korean Med Sci 27: 644-652, 2012.

17. Kang JS, Jeon YJ, Park SK, Yang KH and Kim HM: Protection against lipopolysaccharide-induced sepsis and inhibition of interleukin-1beta and prostaglandin E2 synthesis by silymarin. Biochem Pharmacol 67: 175-181, 2004.

18. Najafzadeh H, Jalali MR, Morovvati $H$ and Taravati F: Comparison of the prophylactic effect of silymarin and deferoxamine on iron overload induced hepatotoxicity in rat. J Med Toxicol 6: 22-26, 2010.

19. Chtourou Y, Garoui E, Boudawara $T$ and Zeghal N: Therapeutic efficacy of silymarin from milk thistle in reducing manganese-induced hepatic damage and apoptosis in rats. Hum Exp Toxicol 32: 70-81, 2013.

20. Panda V, Ashar H and Srinath S: Antioxidant and hepatoprotective effect of Garcinia indica fruit rind in ethanol-induced hepatic damage in rodents. Interdiscip Toxicol 5: 207-213, 2012.

21. Jia R, Cao L, Du J, Xu P, Jeney G and Yin G: The protective effect of silymarin on the carbon tetrachloride $(\mathrm{CCl} 4)$-induced liver injury in common carp (Cyprinus carpio). In Vitro Cell Dev Biol Anim 49: 155-161, 2013.

22. Hermenean A, Stan M, Ardelean A et al: Antiioxidant and hepatoprotective activity of milk thistle (Silybum marianum L. Gaertn.) seed oil. Open Life Sci 10: 225-236, 2015.

23. Das S, Roy P, Auddy RG and Mukherjee A: Silymarin nanoparticle prevents paracetamol-induced hepatotoxicity. Int J Nanomedicine 6 1291-1301, 2011.

24. Mansour HH, Hafez HF and Fahmy NM: Silymarin modulates Cisplatin induced oxidative stress and hepatotoxicity in rats. J Biochem Mol Biol 39: 656-661, 2006.

25. Sasu A, Herman H, Mariasiu T, Rosu M, Balta C, Anghel N, Miutescu E, Cotoraci C and Hermenean A: Protective effects of silymarin on epirubicin-induced mucosal barrier injury of the gastrointestinal tract. Drug Chem Toxicol 38: 442-451, 2015.

26. Rašković A, Stilinović N, Kolarović J, Vasović V, Vukmirović S and Mikov M: The protective effects of silymarin against doxorubicin-induced cardiotoxicity and hepatotoxicity in rats. Molecules 16: 8601-8613, 2011 
27. Vargas-Mendoza N, Madrigal-Santillán E, Morales-González A Esquivel-Soto J, Esquivel-Chirino C, García-Luna Y González-Rubio M, Gayosso-de-Lucio JA and Morales-González JA: Hepatoprotective effect of silymarin. World J Hepatol 6: 144-149, 2014.

28. Karimi G, Vahabzadeh M, Lari P, Rashedinia M and Moshiri M: 'Silymarin', a promising pharmacological agent for treatment of diseases. Iran J Basic Med Sci 14: 308-317, 2011.

29. Tsai JH, Liu JY, Wu TT, Ho PC, Huang CY, Shyu JC, Hsieh YS, Tsai CC and Liu YC: Effects of silymarin on the resolution of liver fibrosis induced by carbon tetrachloride in rats. J Viral Hepat 15: 508-514, 2008.

30. Ahmad I, Shukla S, Kumar A, Singh BK, Kumar V, Chauhan AK, Singh D, Pandey HP and Singh C: Biochemical and molecular mechanisms of $\mathrm{N}$-acetyl cysteine and silymarin-mediated protection against maneb- and paraquat-induced hepatotoxicity in rats. Chem Biol Interact 201: 9-18, 2013.

31. Wu HJ, Liu C, Duan WX, Xu SC, He MD, Chen CH, Wang Y, Zhou Z, Yu ZP, Zhang L and Chen Y: Melatonin ameliorates bisphenol A-induced DNA damage in the germ cells of adult male rats. Mutat Re 752: 57-67, 2013.

32. Roelofs MJ, van den Berg M, Bovee TF, Piersma AH and van Duursen MB: Structural bisphenol analogues differentially target steroidogenesis in murine MA-10 Leydig cells as well as the glucocorticoid receptor. Toxicology 329: 10-20, 2015.

33. Rezg R, El-Fazaa S, Gharbi N and Mornagui B: Bisphenol A and human chronic diseases: Current evidences, possible mechanisms, and future perspectives. Environ Int 64: 83-90, 2014

34. Markiewski MM, DeAngelis RA and Lambris JD: Liver inflammation and regeneration: Two distinct biological phenomena or parallel pathophysiologic processes? Mol Immunol 43: 45-56, 2006.

35. Thoolen B, Maronpot RR, Harada T, Nyska A, Rousseaux C, Nolte T, Malarkey DE, Kaufmann W, Küttler K, Deschl U, et al: Proliferative and nonproliferative lesions of the rat and mouse hepatobiliary system. Toxicol Pathol 38: (7 Suppl) 5S-81S, 2010.

36. Atsafack SS, Kuiate JR, Mouokeu RS, Koanga Mogtomo ML, Tchinda AT, De Dieu TJ, Magnifouet Nana H, Ebelle Etame RM, Biyiti L and Ngono Ngane RA: Toxicological studies of stem bark extract from Schefflera barteri Harms (Araliaceae). BMC Complement Altern Med 15: 44, 2015.

37. Weiss MJ: Cytokines in liver, biliary and pancreatic disease In: Blumgart's Surgery of the Liver, Pancreas and Biliary Tract. Jarnagin W (ed). 5th edition. Elsevier, Inc., Philadelphia, PA, pp166-180, 2012

38. Choi I, Kang HS, Yang Y and Pyun KH: IL-6 induces hepatic inflammation and collagen synthesis in vivo. Clin Exp Immunol 95: 530-535, 1994.

39. Norris CA, He M, Kang LI, Ding MQ, Radder JE, Haynes MM, Yang Y, Paranjpe S, Bowen WC, Orr A, et al: Synthesis of IL-6 by hepatocytes is a normal response to common hepatic Stimuli. PLoS One 9: e96053, 2014.

40. Sherif IO and Al-Gayyar MMH: Antioxidant, anti-inflammatory and hepatoprotective effects of silymarin on hepatic dysfunction induced by sodium nitrite. Eur Cytokine Netw 24: 114-121, 2013.
41. Lovelace ES, Wagoner J, MacDonald J, Bammler T, Bruckner J, Brownell J, Beyer RP, Zink EM, Kim YM, Kyle JE, et al: Silymarin suppresses cellular inflammation by inducing reparative stress signaling. J Nat Prod 78: 1990-2000, 2015.

42. Pękalski J, Zuk PJ, Kochańczyk M, Junkin M, Kellogg R, Tay S and Lipniacki T: Spontaneous NF-kB activation by autocrine TNFa Signaling: A computational analysis. PLoS One 8: e78887, 2013.

43. Kabuto H, Amakawa M and Shishibori T: Exposure to bisphenol A during embryonic/fetal life and infancy increases oxidative injury and causes underdevelopment of the brain and testis inmice. Life Sci 74: 2931-2940, 2004.

44. Korkmaz A, Ahbab MA, Kolankaya D and Barlas N: Influence of vitamin $\mathrm{C}$ on bisphenol $\mathrm{A}$, nonylphenol and octylphenol induced oxidative damages in liver of male rats. Food Chem Toxicol 48: 2865-2871, 2010.

45. Suthar H, Verma RJ, Patel S and Jasrai YT: Green tea potentially ameliorates bisphenol a-induced oxidative stress: An in vitro and in silico study. Biochem Res Int 2014: 259763, 2014.

46. Doerge DR and Fisher JW: Background paper on metabolism and toxicokinetics of bisphenol A. In: Proceedings of the WHO/HSE/FOS/11.1 Expert Meeting on Bisphenol A (BPA '10). World Health Organization, Geneva, 2010.

47. Xia W, Jiang Y, Li Y, Wan Y, Liu J, Ma Y, Mao Z, Chang H, Li G, $\mathrm{Xu} \mathrm{B}$, et al: Early-life exposure to bisphenol a induces liver injury in rats Involvement of mitochondria-mediated apoptosis PLoS One 9: e90443, 2014.

48. Muriel P, Garciapiña T, Perez-Alvarez V and Mourelle M: Silymarin protects against paracetamol-induced lipid peroxidation and liver damage. J Appl Toxicol 12: 439-442, 1992.

49. Jayashree S, Indumathi D, Akilavalli N, Sathish S, Selvaraj J and Balasubramanian K: Effect of Bisphenol-A on insulin signal transduction and glucose oxidation in liver of adult male albino rat. Environ Toxicol Pharmacol 35: 300-310, 2013.

50. Abouzeinab NS: Cytoprotective effect and antioxidant properties of silymarin on cisplatin induced hepatotoxicity in rats: A biochemical and histochemical study. International Journal of Cancer Research 9: 9-23, 2013.

51. Nelson DL and Cox MM (eds): Lehninger Principles of Biochemistry. 5th edition, W.H. Freeman and Co., New York, NY, pp540-550, 2008.

52. Ebaid H, Dkhil MA, Danfour MA, Tohamy A and Gabry MS: Piroxicam-induced hepatic and renal histopathological changes in mice. Libyan J Med 2: 82-89, 2007.

53. Miyamato Y, Shimada K, Sakaguchi Y and Miyamoto M: Cisplatin (CCDP)-induced acute toxicity in an experimental model of hepatic fibrosis. J Toxicol Sci 32: 311-319, 2007.

54. Rosner MH and Okusa M (eds): Biomarkers in Renal Disease. 5th edition. Nova Publishers, New York, NY, pp21-45, 2008.

55. Abdel Salam OM, Sleem AA, Omara EA and Hassan NS: Effect of ribavirin alone or combined with silymarin on carbon tetrachloride induced hepatic damage in rats. Drug Target Insights 2: 19-27, 2007. 